\title{
Electronic and optical device applications of hollow cathode plasma assisted atomic layer deposition based GaN thin films
}

Sami Bolat, Burak Tekcan, Cagla Ozgit-Akgun, Necmi Biyikli, and Ali Kemal Okyay

Citation: Journal of Vacuum Science \& Technology A: Vacuum, Surfaces, and Films 33, 01A143 (2015); doi: 10.1116/1.4903365

View online: http://dx.doi.org/10.1116/1.4903365

View Table of Contents: http://avs.scitation.org/toc/jva/33/1

Published by the American Vacuum Society

\section{Articles you may be interested in}

Demonstration of flexible thin film transistors with GaN channels

Applied Physics Letters 109, 233504 (2016); 10.1063/1.4971837

Low temperature thin film transistors with hollow cathode plasma-assisted atomic layer deposition based GaN channels

Applied Physics Letters 104, 243505 (2014); 10.1063/1.4884061

Atomic layer deposition of $\mathrm{GaN}$ at low temperatures

Journal of Vacuum Science \& Technology A: Vacuum, Surfaces, and Films 30, 01A124 (2011);

10.1116/1.3664102

Comparison of trimethylgallium and triethylgallium as "Ga" source materials for the growth of ultrathin GaN films on Si (100) substrates via hollow-cathode plasma-assisted atomic layer deposition

Journal of Vacuum Science \& Technology A: Vacuum, Surfaces, and Films 34, 01 A137 (2015);

$10.1116 / 1.4937725$

Low-temperature self-limiting atomic layer deposition of wurtzite $\ln N$ on $\mathrm{Si}(100)$

AIP Advances 6, 045203 (2016); 10.1063/1.4946786

Substrate temperature influence on the properties of GaN thin films grown by hollow-cathode plasma-assisted atomic layer deposition

Journal of Vacuum Science \& Technology A: Vacuum, Surfaces, and Films 34, 01 A125 (2015);

$10.1116 / 1.4936230$

Contact Hiden Analytical for further details: W www.HidenAnalytical.com E info@hiden.co.uk CLICK TO VIEW our product catalogue

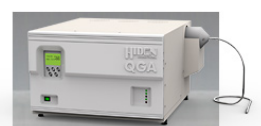

Gas Analysis

dynamic measurement of reaction gas streams , catalysis and thermal analysis molecular beam studies molecular beam studies 'dssolved spectes probes

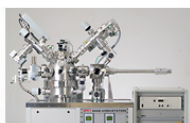

Surface Science

UHVTPD

end point detection in ion beam etch elemental imaging - surface mapping

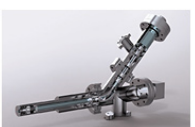

Plasma Diagnostics

plasma source characterization etch and deposition process reaction kinetic studies analysis of neutral and radical species

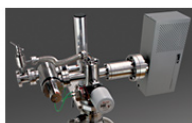

Vacuum Analysis partial pressure measurement and control of process gases reactive sputter process control vacuum diagnostics vacuum coating process monitorin 


\title{
Electronic and optical device applications of hollow cathode plasma assisted atomic layer deposition based GaN thin films
}

\author{
Sami Bolat ${ }^{\text {a) }}$ and Burak Tekcan \\ Department of Electrical and Electronics Engineering, Bilkent University, 06800, Ankara, Turkey and UNAM, \\ National Nanotechnology Research Center, Bilkent University, 06800, Ankara, Turkey \\ Cagla Ozgit-Akgun and Necmi Biyikli \\ UNAM, National Nanotechnology Research Center, Bilkent University, 06800, Ankara, Turkey and Institute \\ of Materials Science and Nanotechnology, Bilkent University, 06800, Ankara, Turkey \\ Ali Kemal Okyay ${ }^{\text {b) }}$ \\ Department of Electrical and Electronics Engineering, Bilkent University, 06800, Ankara, Turkey; UNAM, \\ National Nanotechnology Research Center, Bilkent University, 06800, Ankara, Turkey; and Institute of \\ Materials Science and Nanotechnology, Bilkent University, 06800, Ankara, Turkey
}

(Received 30 August 2014; accepted 21 November 2014; published 16 December 2014)

\begin{abstract}
Electronic and optoelectronic devices, namely, thin film transistors (TFTs) and metalsemiconductor-metal (MSM) photodetectors, based on GaN films grown by hollow cathode plasma-assisted atomic layer deposition (PA-ALD) are demonstrated. Resistivity of GaN thin films and metal-GaN contact resistance are investigated as a function of annealing temperature. Effect of the plasma gas and postmetallization annealing on the performances of the TFTs as well as the effect of the annealing on the performance of MSM photodetectors are studied. Dark current to voltage and responsivity behavior of MSM devices are investigated as well. TFTs with the $\mathrm{N}_{2} / \mathrm{H}_{2}$ PA-ALD based GaN channels are observed to have improved stability and transfer characteristics with respect to $\mathrm{NH}_{3}$ PA-ALD based transistors. Dark current of the MSM photodetectors is suppressed strongly after high-temperature annealing in $\mathrm{N}_{2}: \mathrm{H}_{2}$ ambient. (C) 2014 American Vacuum Society. [http://dx.doi.org/10.1116/1.4903365]
\end{abstract}

\section{INTRODUCTION}

$\mathrm{GaN}$ is known as a transparent compound semiconductor with a bandgap of $3.4 \mathrm{eV}{ }^{1}$ Due to its remarkable optical and electrical properties, intensive research is focused on this material and its applications during the last two decades. ${ }^{2}$ Among other attractive material properties, high electron saturation velocity and wide bandgap make GaN a strong candidate as the material of choice for high-frequency and high-power electronics. ${ }^{3}$ Currently, most commonly used deposition techniques for $\mathrm{GaN}$ epilayers are $\mathrm{MBE}^{4}$ and metalorganic chemical vapor deposition. ${ }^{5}$ However, these high process temperature techniques limit the application areas of the deposited materials. Recently, alternative approaches such as sputtering ${ }^{6}$ and pulsed laser deposition ${ }^{7}$ have been used to obtain GaN films at lower growth temperatures. Moreover, thin film transistors (TFTs) with decent electrical performance have been reported with sputtered GaN channels. ${ }^{8,9}$ In Ref. 8, sputtering is performed at room temperature followed by contact annealing. The authors explain that the contact annealing was performed by a three-step process (room temperature to $400{ }^{\circ} \mathrm{C}$, then to $650{ }^{\circ} \mathrm{C}$, and finally to $850{ }^{\circ} \mathrm{C}$ ) with intermittent delay at each temperature step, to eliminate the cracking problem of the thin films. However, they do not mention the dwell times at each annealing temperature, which is very crucial for the crystalline quality of the GaN films. The authors do not report any crystal properties before or after the contact anneal in Ref. 8. In their

\footnotetext{
a)Electronic mail: bolat@ee.bilkent.edu.tr

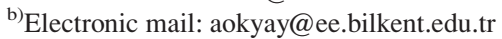

following study, ${ }^{9}$ the authors deposit the GaN film at a temperature of $550{ }^{\circ} \mathrm{C}$ by sputtering. At this temperature, a wurtzite crystal structure was obtained. Moreover, a $55 \mathrm{~min}$ $500{ }^{\circ} \mathrm{C}$ postdeposition contact anneal was conducted; however, crystal properties after this relatively long anneal step were not reported as well. In addition to the techniques above, atomic layer deposition (ALD) is an alternative method for large area thin film applications such as flexible electronics and photovoltaic cells, as well as thin film transistors, which attracted significant interest recently. There are limited reports on the use of plasma-assisted ALD techniques for the deposition of GaN thin films including the authors' own work. ${ }^{10-12}$

ALD is a modified chemical vapor deposition (CVD) technique, in which the introduction of different precursors is separated by intermittent evacuation and/or purging steps. This method is recognized by its self-limiting growth, which enables the deposition of highly conformal and uniform thin films with mono layer thickness control. Owing to these features, ALD technique earned an unrivaled seat in the CMOS technology for the deposition of high-k dielectrics. ${ }^{13}$ Hollow cathode plasma-assisted atomic layer deposition (HCPAALD) is a modified version of PA-ALD which uses a hollow cathode plasma source for the creation of the ions of one of the precursors used in the deposition of the thin films. This method, when compared to conventional PA-ALD systems utilizing inductively coupled plasma sources, has been shown to have better film characteristics with the reduced oxygen concentration in the deposited III-nitride thin films. ${ }^{12}$ Although a proof of principle device based on ALD grown $\mathrm{GaN}$ has been demonstrated by the authors, ${ }^{14}$ the effects of 
the plasma gas used and postmetallization annealing on TFT performance have not been studied. In addition, the effect of the annealing temperature on HCPA-ALD GaN metal-semiconductor-metal (MSM) photodetector performance is yet to be reported.

Here, we report the structural, electrical, and optical properties of GaN thin films deposited by HCPA-ALD at a low substrate temperature of $200^{\circ} \mathrm{C}$. We also demonstrate the use of ALD-grown GaN thin films as channels of bottom gate TFTs as well as the active layers of MSM photodetectors. Electrical characteristics of the fabricated TFTs, the optical characteristics of the MSM photodetectors, and the effect of postannealing on the device performances are discussed in detail.

\section{EXPERIMENT}

\section{A. Structural and electrical characterization of the GaN thin films and TFTs}

GaN thin films are deposited by HCPA-ALD using trimethylgallium ( $\mathrm{TMGa}$ or $\mathrm{GaMe}_{3}$ ) as the Ga precursor and $\mathrm{NH}_{3}$ plasma or $\mathrm{N}_{2} / \mathrm{H}_{2}(1 / 1)$ plasma as nitrogen precursor in an Ultratech/Cambridge Nanotech Fiji F200-LL ALD reactor. Details of the material growth can be found elsewhere. ${ }^{12}$ Van der Pauw and cross-bridge Kelvin resistor (CBKR) structures are designed and fabricated for sheet resistance and contact resistance measurements, respectively.

Figure 1 depicts the proposed bottom gate TFTs in this work. TFT fabrication process begins with the standard RCA cleaning of low resistivity p-type $(1-5 \mathrm{~m} \Omega \mathrm{cm}) \mathrm{Si}$ substrate, which is also employed as the bottom gate terminal of the TFT. Next, a 200-nm-thick $\mathrm{SiO}_{2}$ layer is deposited by plasma-enhanced $\mathrm{CVD}$ at $250^{\circ} \mathrm{C}$ to achieve electrical isolation between the source-drain contacts and the $\mathrm{Si}$ bottom gate. Then, active device areas are patterned by photolithography and wet etching of $\mathrm{SiO}_{2}$. This is followed by the thermal and HCPA-ALD of $\mathrm{Al}_{2} \mathrm{O}_{3}$ and $\mathrm{GaN}$ (grown by $\mathrm{NH}_{3}$ ) $(30 \mathrm{~nm} / 20 \mathrm{~nm})$ gate stack at $20{ }^{\circ} \mathrm{C}$, respectively. Afterward, channel region is patterned via photolithography and dry etching of $\mathrm{GaN}$ thin films. Ti $(20 \mathrm{~nm}) / \mathrm{Au}(80 \mathrm{~nm})$ source and drain electrodes are sputtered and then patterned by the lift-off technique. Finally, contact annealing is performed at $600{ }^{\circ} \mathrm{C}$ in $\mathrm{N}_{2}$ ambient for $30 \mathrm{~s}$ using a rapid thermal

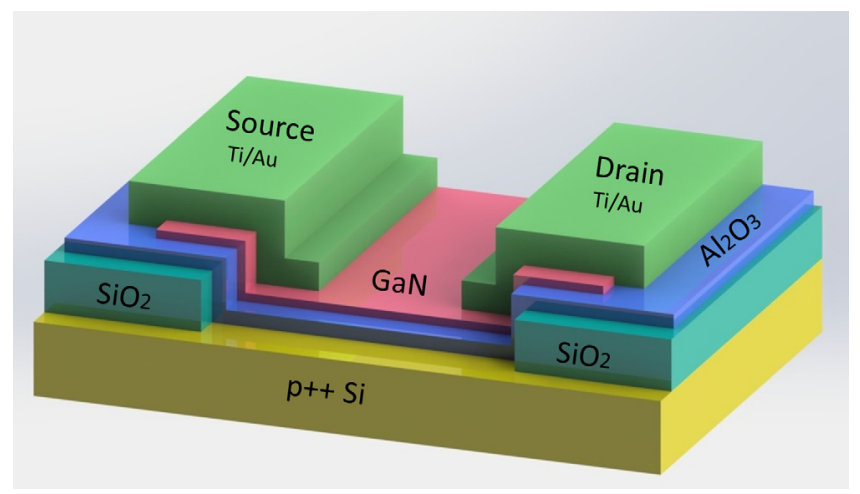

FIG. 1. (Color online) Schematic representation of the bottom gate TFT with HCPA-ALD-grown GaN channel layer. annealing system (RTA). To determine the effect of the $\mathrm{N}$ precursor on the device performance, TFTs with GaN channels grown by $\mathrm{N}_{2} / \mathrm{H}_{2}$ PA-ALD method are also realized. Fabrication details of such devices can be found elsewhere. ${ }^{14}$

Sheet resistance and contact resistance measurements are conducted on the films before and after the contact annealing at 400,600 , and $800^{\circ} \mathrm{C}$, separately for each annealing temperature, using Keithley 4200 semiconductor parameter analyzer (SPA). Transfer and output characteristics of the TFTs before and after contact annealing steps are also obtained by Keithley 4200 SPA.

\section{B. MSM photodetector fabrication and characterization}

As the starting substrate of the MSM photodetectors, silicon wafer coated with $100 \mathrm{~nm}$ thermally grown $\mathrm{SiO}_{2}$ is used. GaN layers are deposited by using TMGa as Ga precursor and $\mathrm{N}_{2} / \mathrm{H}_{2}$ plasma as $\mathrm{N}$ source. Thickness of the thin film is measured using spectroscopic ellipsometry system and found to be $20 \mathrm{~nm}$. Samples are cleaned with acetone, isopropanol, and DI water, then dipped into dilute $\mathrm{HF}$ solution $\left(\mathrm{H}_{2} \mathrm{O}: \mathrm{HF}\right.$ 50:1) to get rid of native oxide on the GaN surface and rinsed with DI water. Following the cleaning, metal contacts, $\mathrm{Ti}(20 \mathrm{~nm}) / \mathrm{Au}(100 \mathrm{~nm})$, are formed via sputtering and lift-off technique. To observe the effect of the annealing on the device performance, the films are annealed at $800^{\circ} \mathrm{C}$ for 30 min just prior to the contact metal deposition. Films are annealed either in $\mathrm{N}_{2}$ or (95\%:5\%) $\mathrm{N}_{2}: \mathrm{H}_{2}$ (forming gas) ambient in a rapid thermal annealing furnace.

MSM photodetectors are electrically characterized using the same SPA system. The dark current-voltage (I-V) characteristics are obtained in the range between -30 and $30 \mathrm{~V}$. Spectral photo-responsivity measurements are performed using a $150 \mathrm{~W}$ Xenon light source and Newport Oriel 1/8m Cornerstone monochromator. The incident monochromatic light is mechanically modulated using an optical chopper and photo-generated electrical current is recorded with SRS830 dual phase lock-in amplifier. Bias voltage is applied using a Keithley 2400 sourcemeter during spectral photoresponsivity measurements. Photoresponse is measured within the $290-400 \mathrm{~nm}$ spectral range. These devices are also reverse biased from 0 to $-10 \mathrm{~V}$ to analyze the biasdependence of detector photoresponse.

\section{RESULTS AND DISCUSSION}

GIXRD patterns of the as-deposited GaN thin films reveal the poly-crystalline wurtzite structure of the as-deposited layers. ${ }^{12}$ Crystallite size is calculated using line profile analysis and found to be $10.2 \mathrm{~nm}$ in $\mathrm{NH}_{3}$ PA-ALD grown $\mathrm{GaN}$ thin film, whereas the $\mathrm{N}_{2} \mathrm{H}_{2}$ PA-ALD GaN thin film is shown to have a crystallite size of $9.3 \mathrm{~nm}$. Annealing the thin films at temperature levels as high as $800^{\circ} \mathrm{C}$ is shown not to cause a significant change in the structural properties of HCPAALD based GaN layers. ${ }^{15}$ Composition as a function of depth is determined by XPS measurements, which revealed 42.19 at. $\% \mathrm{Ga}, 55.18$ at. $\% \mathrm{~N}, 1.51$ at. $\% \mathrm{O}$, and 1.13 at. \% 
Ar in the $\mathrm{NH}_{3}$ PA-ALD based GaN thin film after $60 \mathrm{~s}$ of $i n$ situ $\mathrm{Ar}$ ion etching. $\mathrm{N}_{2} \mathrm{H}_{2}$ PA-ALD GaN thin film, on the other hand, is shown to have 42.24 at. \% Ga, 54.57 at. \% N, 1.65 at. $\% \mathrm{O}$, and 1.54 at. $\% \mathrm{Ar}$ after $60 \mathrm{~s}$ of Ar ion etching. These results, at first glance, seem to show nitrogen-rich composition for the as-deposited thin films. However, it should be noticed that nitrogen concentration is overestimated due to the contribution of Auger Ga peaks that overlap with the $\mathrm{N}$ 1s peak in XPS spectrum.

To investigate the electrical properties of $\mathrm{NH}_{3}$ PA-ALD based GaN thin films and contacts with the Ti/Au metal stack (used in Ref. 9 as the source/drain contact), resistivity, and contact resistance measurements are performed on Van der Pauw and CBKR structures, respectively. Table I summarizes the results of these measurements.

There is a slight decrease in the resistivity of GaN thin films with increasing annealing temperature up to $600^{\circ} \mathrm{C}$, which can be attributed to the hydrogen releasing. After annealing at $800^{\circ} \mathrm{C}$, however, resistivity of the film significantly drops (more than $40 \times$ ) down to $9.6 \Omega \mathrm{cm}$. Moreover, the contact resistance between $\mathrm{GaN}$ and $\mathrm{Ti} / \mathrm{Au}$ stack is reduced significantly (more than $4000 \times$ ) to $10^{-3} \Omega \mathrm{cm}^{2}$. However, the film surface is severely deformed after annealing at $800^{\circ} \mathrm{C}$, forming blisters. This morphological change may have several reasons such as the hydrogen impurity concentration in the deposited $\mathrm{GaN}$ thin film, and thermal expansion mismatch between the different layers. However, we believe that the main reason here is the high hydrogen concentration which was confirmed by the secondary ion mass spectroscopy compositional analysis results. ${ }^{12} \mathrm{~N}_{2}$ plasma might be used instead of $\mathrm{NH}_{3}$ plasma to eliminate $\mathrm{H}$ incorporation in the deposited film. ${ }^{12}$ Hydrogen, with a rapid increase in temperature, is known to cause blistering in annealed films beyond a critical temperature. ${ }^{16-18}$ Elemental hydrogen, if incorporated into GaN thin films, is also known to passivate crystal imperfections such as dangling bonds and vacancies. ${ }^{19}$ Owing to this property, $\mathrm{H}$-atoms electrically compensate the defect-related charge carrier concentration in the deposited material. ${ }^{19}$ Upon annealing at high temperatures (such as $800^{\circ} \mathrm{C}$ ) pockets of molecular hydrogen form blisters in the film and hydrogen gas is released via these micro cracks. Due to reduced hydrogen concentration, defect-related charge carrier density in such films is increased. This is supported by the significantly lower resistivity of the films after annealing at $800^{\circ} \mathrm{C}$ for $30 \mathrm{~s}$. In order to reduce the resistivity of the thin films as well as to minimize their contact resistance with $\mathrm{Ti} / \mathrm{Au}$ layers without

TABLE I. Resistivity of GaN thin films and the contact resistance between $\mathrm{GaN}$ and $\mathrm{Ti} / \mathrm{Au}$ metallization scheme after annealing at different temperatures.

\begin{tabular}{lcc}
\hline \hline Annealing details & Resistivity $(\Omega \mathrm{cm})$ & Contact resistance $\left(\Omega \mathrm{cm}^{2}\right)$ \\
\hline As-deposited & 475.7 & 4.124 \\
$400^{\circ} \mathrm{C}, 30 \mathrm{~s}$ & 423.2 & 3.258 \\
$600^{\circ} \mathrm{C}, 30 \mathrm{~s}$ & 410.4 & 3.243 \\
$800^{\circ} \mathrm{C}, 30 \mathrm{~s}$ & 9.6 & 0.001 \\
\hline \hline
\end{tabular}

deforming the GaN surface, contact annealing of the TFTs with such channels are performed at $600^{\circ} \mathrm{C}$, for $30 \mathrm{~s}$ in $\mathrm{N}_{2}$ ambient.

Transfer characteristics of the TFT with bottom-gate configuration and W/L of $50 \mu \mathrm{m} / 50 \mu \mathrm{m}$ are obtained by sweeping the gate to source voltage $\left(\mathrm{V}_{\mathrm{GS}}\right)$ from 7 to $12 \mathrm{~V}$, while the drain to source voltage $\left(\mathrm{V}_{\mathrm{DS}}\right)$ is kept at $1 \mathrm{~V}$. As shown in Fig. 2(a), the device has an $\mathrm{I}_{\mathrm{ON}} / \mathrm{I}_{\mathrm{OFF}}$ ratio of $4.7 \times 10^{2}$, and a subthreshold swing of $1.5 \mathrm{~V} / \mathrm{dec}$. Extracted threshold voltage from $\mathrm{I}_{\mathrm{DS}} \mathrm{vs}_{\mathrm{GS}} \mathrm{V}_{\mathrm{GS}}$ graph is $8.2 \mathrm{~V}$. The reason for having relatively low on-to-off ratio can be attributed to the high resistivity of the deposited $\mathrm{GaN}$ thin films.

Field effect mobility of the device in the linear operation region is found to be $8 \times 10^{-3} \mathrm{~cm}^{2} / \mathrm{V}$ s. Low carrier mobility could be related to the trap states at the semiconductor-insulator interface and the polycrystalline defect-rich nature of the deposited GaN thin films. Output characteristics of the same device are shown in Fig. 2(b) to exhibit traditional n-type enhancement mode field effect transistor behavior, having clear pinch-off and saturation characteristics. Gate control is also clear with the fact that increased gate voltage results in increased drain current implying well-behaved saturation region characteristics.

Next, to analyze the effect of the plasma gas choice on the device performance, TFTs with $\mathrm{N}_{2} / \mathrm{H}_{2}$ PA-ALD based GaN channels are fabricated and their transfer characteristics are obtained. Transfer characteristics of such a device reveal that on-to-off ratio is $2 \times 10^{3}$ in a nonannealed device. This device is also shown to have a threshold voltage of $11.8 \mathrm{~V}$ and the field effect mobility is obtained to be $0.025 \mathrm{~cm}^{2} / \mathrm{V} \mathrm{s}$

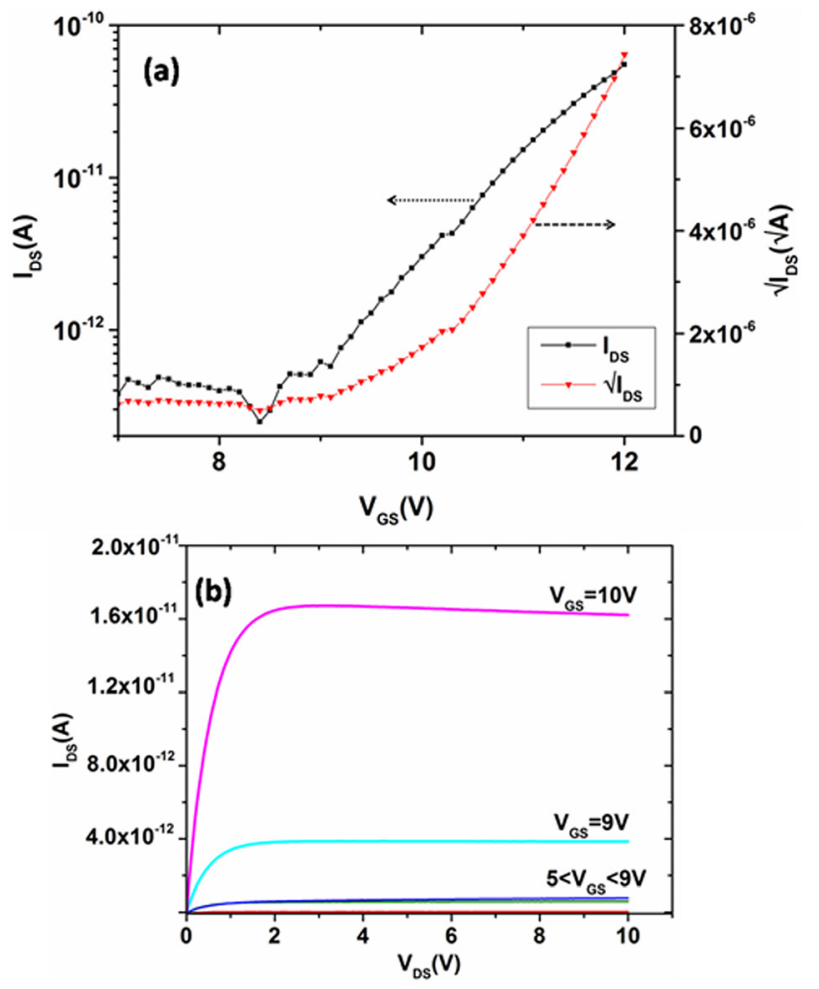

FIG. 2. (Color online) (a) Transfer and (b) output characteristics of the TFTs with HCPA-ALD based GaN active layers using $\mathrm{NH}_{3}$ as the plasma gas. 
( $3 \times$ improvement compared to $\mathrm{NH}_{3}$ case). With all the fabrication steps performed at temperature levels lower than $250{ }^{\circ} \mathrm{C}$, this device is realized as the $\mathrm{GaN}$ transistor with the lowest thermal budget reported so far. ${ }^{14}$

To determine the effect of contact annealing on the device performance, TFTs with $\mathrm{N}_{2} / \mathrm{H}_{2}$ PA-ALD based GaN channels are annealed at 600 and $800{ }^{\circ} \mathrm{C}$, and their transfer characteristics are depicted in Fig. 3 alongside a virgin device. The on-to-off ratio of the devices are increased to $7 \times 10^{3}$ after annealing at $600{ }^{\circ} \mathrm{C}$ and the threshold voltage of the device is extracted to be $17.5 \mathrm{~V}$. After the annealing is performed at $800{ }^{\circ} \mathrm{C}$ on a virgin device, on the other hand, the ratio is obtained as $2 \times 10^{4}(10 \times$ improvement compared to as-deposited), and the threshold voltage is extracted as 16.1 V. It is observed that the off current is decreased for both of the annealed devices when compared to the nonannealed one. It can be attributed to the annealing that results in the passivation of the some defect sites, thereby resulting in a lower carrier concentration in the channel region. These results show that the contact annealing process increases the threshold voltage of the devices, as well as the on-to-off current ratios. The increase in the on-to-off ratio is mainly caused by the reduced off current. The increase in the threshold voltage, on the other hand, can be attributed to the slight decrease of the carrier concentration of the channel layer, after the annealing is performed. In addition, as seen in Fig. 4, after the contact anneal is performed at $800^{\circ} \mathrm{C}$, the gate leakage of the device is noted to increase in the off-state, while it is reduced in the on-state of the transistor operation. Moreover, the transfer characteristics of the postannealed devices are observed to be the same after the measurement is repeated for five times (see Fig. 5). This shows that the stability of the device increases with the help of this anneal step.

After the realization of an electronic device based on HCPA-ALD grown GaN thin films, the optical properties of such films are investigated with the demonstration of the first MSM photodetector with ALD based GaN active layer,

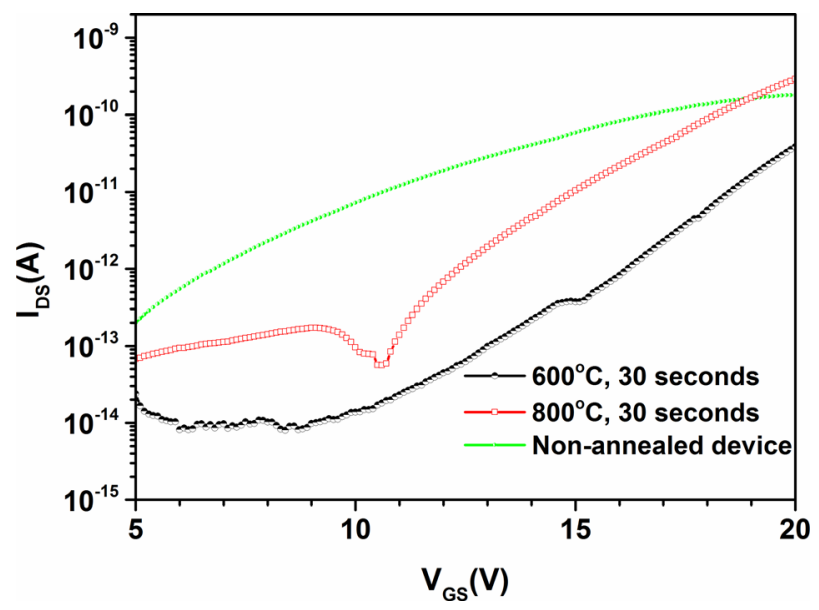

FIG. 3. (Color online) Transfer characteristics of the $\mathrm{N}_{2} / \mathrm{H}_{2}$ PA-ALD based TFTs before annealing (dotted curve) and after the contact annealing is performed at $600{ }^{\circ} \mathrm{C}$ (curve with circular symbols) and $800^{\circ} \mathrm{C}$ (curve with square shaped symbols).

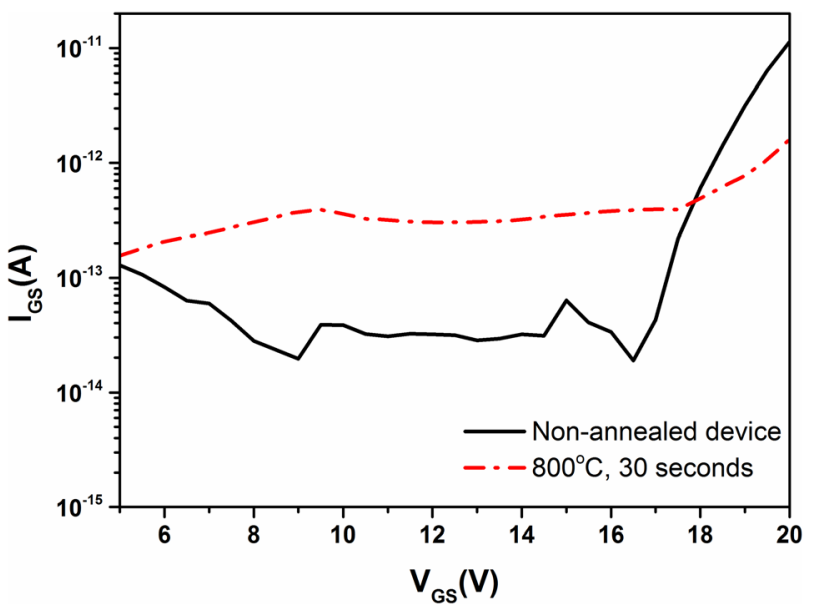

FIG. 4. (Color online) Gate current (leakage) of the $\mathrm{N}_{2} / \mathrm{H}_{2}$ PA-ALD grown $\mathrm{GaN}$ based TFT before (solid) and after the contact anneal at $800^{\circ} \mathrm{C}$ (dashed).

scanning electron microscope (SEM) image of which is shown in Fig. 6. The current-voltage characteristics of the fabricated devices are shown in Fig. 7. Devices fabricated on as-deposited GaN films exhibit very low leakage current levels of $20 \mathrm{pA}$ at $-20 \mathrm{~V}$, which is desirable for high signalto-noise ratio. Devices built on films annealed in $\mathrm{N}_{2}: \mathrm{H}_{2}$ environment exhibit even further-reduced dark current levels down to $50 \mathrm{fA}$ at $-20 \mathrm{~V}$. This dark current value is among the lowest values reported in the literature for GaN MSMs and it is comparable to that of epilayer films. ${ }^{20}$ The reduced dark current is attributed to hydrogen incorporation into the film and passivation of the defect sites during the annealing process. ${ }^{12,21}$ On the other hand, films annealed in $\mathrm{N}_{2}$ environment display significantly higher dark currents in the few hundred $\mathrm{nA}$ level at $-20 \mathrm{~V}$. This behavior might be attributed to the increased electrically active defect density caused by hydrogen outgassing as described above, which in turn, increased the free carrier concentration in the GaN layer.

The spectral photo-response characteristics of the fabricated MSM photo-detector devices are illustrated in Fig. 8.

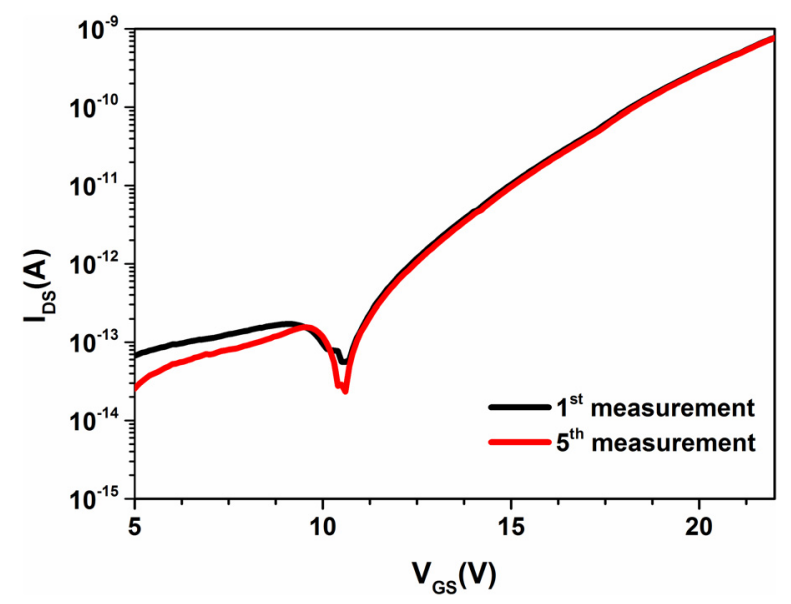

FIG. 5. (Color online) Transfer characteristics of TFTs including contact annealing at $800^{\circ} \mathrm{C}$, after the measurements are performed for the first time(upper curve) and after the measurements are repeated for five times (lower curve). 


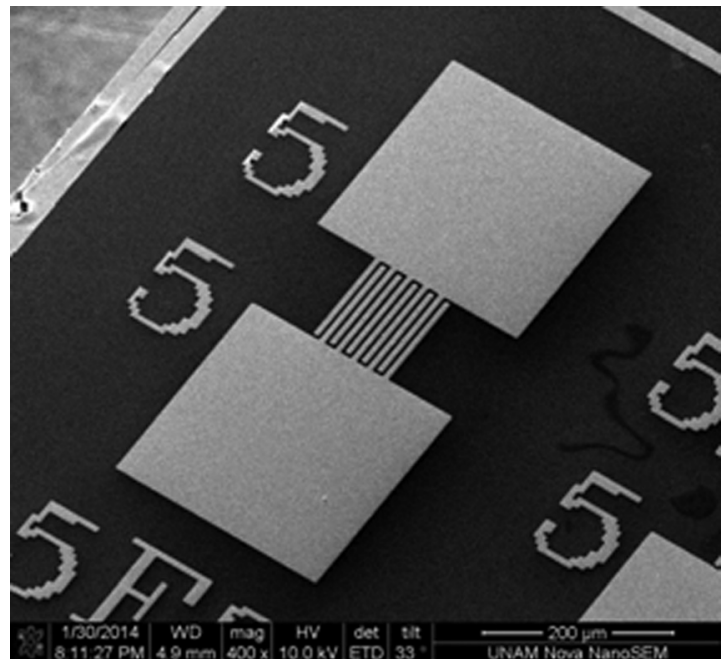

FIG. 6. SEM image of the MSM photodetector.

The responsivity value decreases significantly at wavelengths $>300 \mathrm{~nm}$ due to the band edge of HCPA-ALDgrown GaN film as verified by the optical transmission measurements as well. ${ }^{12,15}$ Fabricated devices show responsivity values of $0.95,0.68$, and $0.47 \mathrm{~mA} / \mathrm{W}$ at a wavelength of $300 \mathrm{~nm}$ for annealed (in $\mathrm{N}_{2}: \mathrm{H}_{2}$ and $\mathrm{N}_{2}$ ambient) and asdeposited GaN films, respectively, under $7 \mathrm{~V}$ reverse bias. Annealing the $\mathrm{GaN}$ film in $\mathrm{N}_{2}: \mathrm{H}_{2}$ environment significantly increases the responsivity in the UV region due to increased collection efficiency of photo-generated carriers. This is attributed to the decrease in the number of defect sites during annealing and hydrogen doping of the film. ${ }^{21}$ On the other hand, annealing the samples in $\mathrm{N}_{2}$ ambient results in a broad increase in spectral photoresponse including the sub-band gap visible region. This is attributed to the introduction of deep level traps within the forbidden gap due to nitrogen incorporation. ${ }^{22,23}$ Nitrogen-rich GaN favors negatively charged $\mathrm{Ga}$ vacancies, which introduce acceptor states. ${ }^{22}$ Furthermore, nitrogen interstitials are believed to be responsible for acceptorlike deep trap states. ${ }^{23}$ Such defect states promote photoconductive gain that increases responsivity in

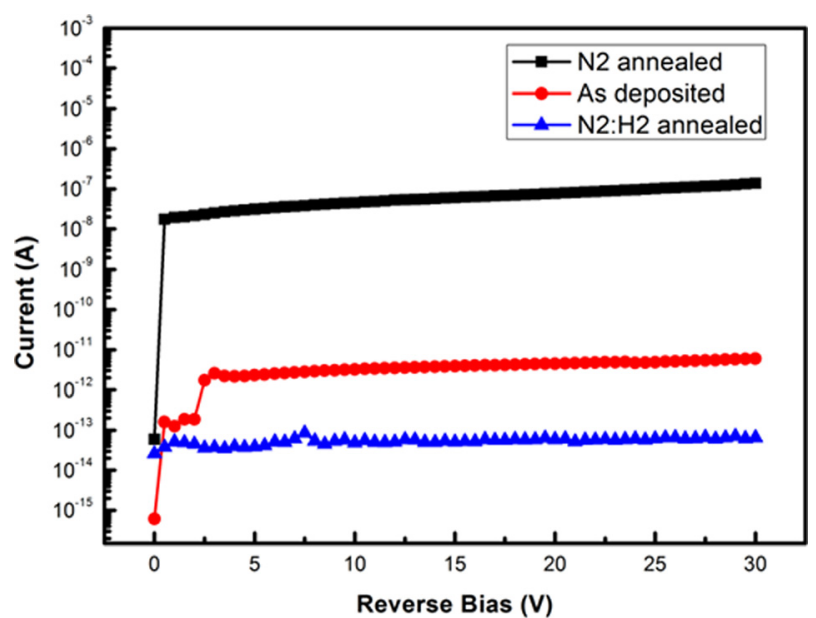

FIG. 7. (Color online) GaN MSM photodetector dark current-voltage characteristics.

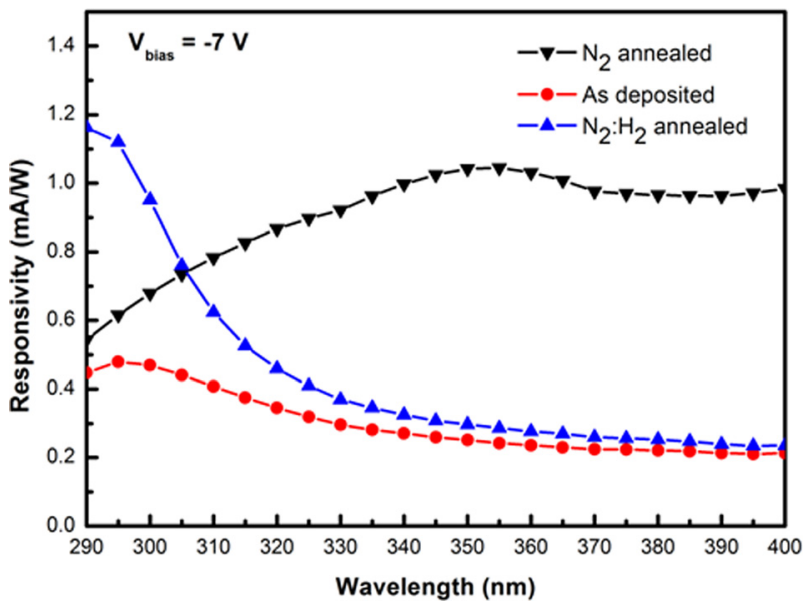

FIG. 8. (Color online) Spectral responsivity of the fabricated GaN MSM photo-detectors for as-deposited and annealed (in $\mathrm{N}_{2}: \mathrm{H}_{2}$ and $\mathrm{N}_{2}$ ambient) samples.

UV region, as well as defect-assisted photon absorption resulting in increased responsivity for sub-band gap excitation. $^{23,24}$

Responsivity values with respect to applied voltage in the reverse bias region are shown in Fig. 9. Wavelength of the incident light is kept constant at $300 \mathrm{~nm}$. The responsivity values increase as the applied bias increases due to the more efficient collection of photo-generated carriers. The saturation behavior is attributed to depletion of the $\mathrm{GaN}$ layer under higher applied voltages. The slight increase of the responsivity at high voltages is believed to be related to photoconductive gain mechanism. ${ }^{24}$

\section{SUMMARY AND CONCLUSIONS}

The structural, electrical, and optical properties of the GaN thin films deposited by $\mathrm{N}_{2} / \mathrm{H}_{2}$ and $\mathrm{NH}_{3}$ PA-ALD technique are studied, and the effect of contact annealing on the resistivity of thin film and its contact resistance with $\mathrm{Ti} / \mathrm{Au}$ contacts is presented. The first device application of such films is presented with the fabrication of TFTs in the bottom gate configuration. The effect of the $\mathrm{N}$ precursor on the

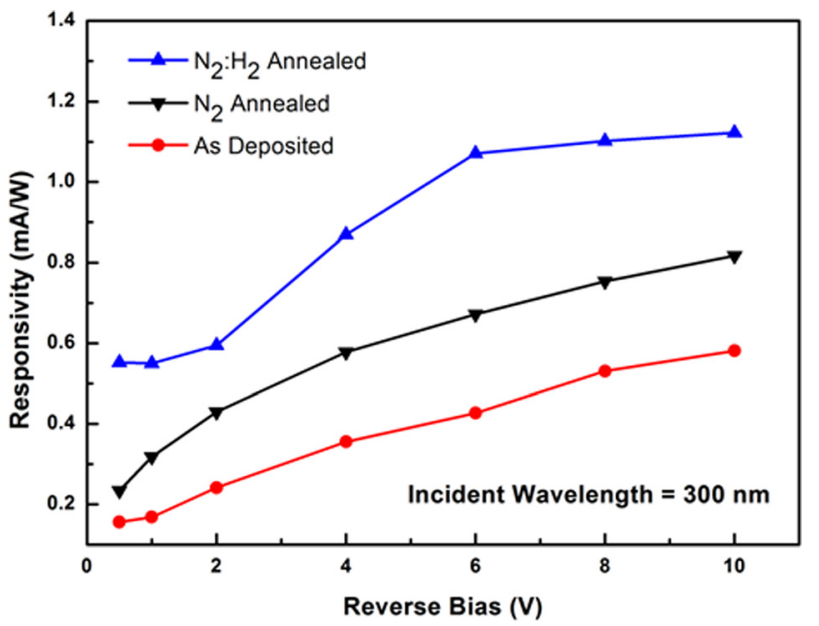

FIG. 9. (Color online) Responsivity values of the fabricated devices with respect to applied reverse bias voltage. 
device performance is also studied, and it is shown that the $\mathrm{N}_{2} / \mathrm{H}_{2}$ PA-ALD based GaN thin films yield better performances in the TFT and MSM applications. The effect of contact annealing on the device performances are also studied, and it is demonstrated that the contact annealing increases the on-to-off ratio of the TFT devices. Despite the increased gate leakage current in the off state, the contact annealing step, when performed at $800^{\circ} \mathrm{C}$ for $30 \mathrm{~s}$, is observed to increase the stability of the TFTs. Optical properties of the HCPA-ALD based GaN thin films are also investigated with the demonstration of the first MSM photodetector based on such films. The effect of the annealing on the responsivity of such devices is also studied and it has been shown that the enhanced responsivity values are obtained in the devices with GaN thin films annealed in the $\mathrm{N}_{2}: \mathrm{H}_{2}$ environment where the dark current is strongly suppressed due to the hydrogen incorporation into the annealed film.

\section{ACKNOWLEDGMENTS}

This work was supported by the Scientific and Technological Research Council of Turkey (TUBITAK), Grant Nos. 112M004, 112E052, 112M482, and 113M815. S.B. and B.T. acknowledge TUBITAK-BIDEB for national Ph.D. and M.Sc. fellowships, respectively. N.B. acknowledges support from European Union FP7 Marie Curie International Reintegration Grant (NEMSmart, Grant No. PIRG05-GA-2009-249196). A.K.O. acknowledges support from Marie Curie International Reintegration Grant (PIOS, Grant No. PIRG04-GA-2008-239444) and the Turkish Academy of Sciences Distinguished Young Scientist Award (TUBA-GEBIP).

${ }^{1}$ H. Morkoç, S. Strite, G. B. Gao, M. E. Lin, B. Sverdlov, and M. Burns, J. Appl. Phys. 76, 1363 (1994).

${ }^{2}$ A. Krost and A. Dadgar, Phys. State Solidi A 194, 361 (2002).
${ }^{3}$ J. S. Moon, M. Micovic, P. Janke, P. Hashimoto, W. S. Wong, R. D. Widman, L. McCray, A. Kurdoghlian, and C. Nguyen, Electron. Lett. 37, 528 (2001).

${ }^{4}$ E. J. Tarsa, B. Heying, X. H. Wu, P. Fini, S. P. Den Baars, and J. S. Speck, J. Appl. Phys. 82, 5472 (1997).

${ }^{5}$ S. Nakamura, Y. Harada, and M. Seno, Appl. Phys. Lett. 58, 2021 (1991).

${ }^{6}$ R. Chen, W. Zhou, and H. S. Kwok, Appl. Phys. Lett. 100, 022111 (2012).

${ }^{7}$ R. D. Vispute et al., Appl. Phys. Lett. 71, 102 (1997).

${ }^{8}$ R. Chen, W. Zhou, M. Zhang, and H. S. Kwok, IEEE Electron Device Lett. 34, 517 (2013).

${ }^{9}$ R. Chen, W. Zhou, M. Zhang, and H. S. Kwok, IEEE Electron Device Lett. 33, 1282 (2012).

${ }^{10}$ T. R. Sharp, A. K. Peter, C. J. Hodson, B. MacKenzie, C. Pugh, M. Loveday, and R. Gunn, paper presented at the 13th International Conference on Atomic Layer Deposition, San Diego, July, 2013.

${ }^{11}$ O. H. Kim, D. Kim, and T. Anderson, J. Vac. Sci. Technol., A 27, 923 (2009).

${ }^{12}$ C. Ozgit-Akgun, E. Goldenberg, A. K. Okyay, and N. Biyikli, J. Mater. Chem. C 2, 2123 (2014).

13،"International Technology Roadmap for Semiconductors," Semiconductor Industry Association, 2011.

${ }^{14}$ S. Bolat, C. Ozgit-Akgun, B. Tekcan, N. Biyikli, and A. K. Okyay, Appl. Phys. Lett. 104, 243505 (2014).

${ }^{15}$ E. Goldenberg, C. Ozgit-Akgun, N. Biyikli, and A. K. Okyay, J. Vac. Sci. Technol., A 32, 031508 (2014).

${ }^{16}$ S. O. Kucheyev, J. S. Williams, C. Jagadish, J. Zou, and G. Li, J. Appl. Phys. 91, 3928 (2002).

${ }^{17}$ S. W. Bedell and W. A. Lanford, J. Appl. Phys. 90, 1138 (2001).

${ }^{18}$ M. Bruel, B. Aspar, and A.-J. Auberton-Hervé, Jpn. J. Appl. Phys., Part 1 36, 1636 (1997).

${ }^{19}$ S. J. Pearton, C. R. Abernathy, R. G. Wilson, J. M. Zavada, C. Y. Song, M. G. Weinstein, M. Stavola, J. Han, and R. J. Shul, Nucl. Instrum. Methods Phys. Res., Sect. B 147, 171 (1999).

${ }^{20}$ J. C. Carrano, T. Li, P. A. Grudowski, C. J. Eiting, R. D. Dupuis, and J. C. Campbell, Electron. Lett. 33, 1980 (1997).

${ }^{21}$ C. G. Van de Walle, Phys. Rev. B. 56, R10020(R) (1997).

${ }^{22}$ E. Muñoz, E. Monroy, J. A. Garrido, I. Izpura, F. J. Sánchez, M. A. Sánchez-Garca, E. Calleja, B. Beaumont, and P. Gibart, Appl. Phys. Lett. 71, 870 (1997).

${ }^{23}$ M. A. Reshchikov and H. Morkoç, J. Appl. Phys. 97, 061301 (2005).

${ }^{24}$ J. A. Garrido, E. Monroy, I. Izpura, and E. Munoz, Semicond. Sci. Technol. 13, 563 (1998). 